\title{
A Case Study in Applied Oceanography: The Lifting and Moving of the Ehime Maru
}

\author{
William H. Little \\ Naval Pacific Meteorology and Oceanography Center \\ Joint Typhoon Warning Center - Pearl Harbor, Hawaii USA
}

\section{Introduction}

At approximately 1:45 PM in the afternoon of February 9, 2001, a Los Angeles class submarine of the U.S. Navy, USS Greeneville, accidentally collided with the Japanese longline training and fishing vessel, Ehime Maru. The incident occurred approximately nine nautical miles south of the Hawaiian Island of Oahu. The 56 meter, 830 ton, Ehime Maru plunged to the ocean floor 650 meters below. Twenty-six of the 35 crewmembers were pulled from the sea by rescue teams, while the rest of the crew remained missing after several days of search and rescue operations. It was presumed they were trapped within the vessel or lost overboard as the Ehime Maru sunk. A few days later, after underwater submersibles were brought to the scene, it was discovered that no human remains were lying near the sunken hull. The probability increased that the lost crew were trapped inside.

Under a backdrop of national and international pressure and the general feeling that the Navy caused the accident, the Navy decided to explore the option of raising the Ehime Maru to recover the bodies of the deceased crew members. The Navy began conducting extensive engineering analyses, building an environmental assessment, and performing numerous underwater surveys by Navy and contracted remotely operated vehicles (ROV). Based on the results of this effort, the Navy decided to attempt to lift the Ehime Maru from the seafloor, move it to a location within the safe depth for SCUBA, recover the missing crew, and dispose of the ship in deep water. The divers were tasked to thoroughly search the interior of the Ehime Maru and recover the bodies of the missing crew members and any personal effects remaining aboard. The mission was to be conducted in a manner sensitive to the Japanese culture, and the greatest possible consideration was to be given to the families that lost their loved ones. The families would be continuously updated by the Navy and invited to watch all operations as they unfolded.

At the outset Admiral William Klemm, who was assigned to oversee this mission, felt that the project had an 80 percent chance of success. Further he issued both a directive and a challenge that applied to the entire operation: "Not a single teaspoon of oil will get onto any Hawaiian beach." As a result of the technical scope of this engineering project and Admiral Klemm's order, this operation became a very focused oceanographic challenge.

\section{Oceanographic Data Collection}

The oceanographic data collection operations centered on understanding the bathymetry, sediments, and currents at the deep water recovery site (DWRS), along the route between the DWRS and the shallow water recovery site (SWRS), and at the SWRS. The U.S. Naval Oceanographic Office provided the USNS Sumner (TAGS 61), a multi-purpose oceanographic survey ship operated by the Military Sealift Command, for two oceanographic data collection periods during this operation. The first oceanographic data collection operation was conducted during June 17-28, and consisted of 43 Conductivity-Temperature-Depth (CTD) station measurements and the deployment of Acoustic Doppler Current Profiler (ADCP) instruments at the DWRS and the SWRS. This was followed by a second oceanographic data collection period from July 17-20, and consisted of 15 CTD station measurements, retrieval of the ADCP equipment, and installation of two Texas Automated Buoy Systems (TABS) east and west of the SWRS. Additionally, USNS Sumner collected bathymetric data, sediment core samples at both the DWRS and SWRS, and hull-mounted ADCP current data over the entire operations area as they transited to and from the DWRS to SWRS (Carnes et al., 2001).

\section{Bathymetric Data}

There were no expectations of any bathymetric difficulties. Figure (1) shows, in a 3-D rendering from the Naval Oceanographic Office, the location of the WRS, the SWRS, and the final disposition site. Repeated measurements during numerous USNS Sumner tran- 


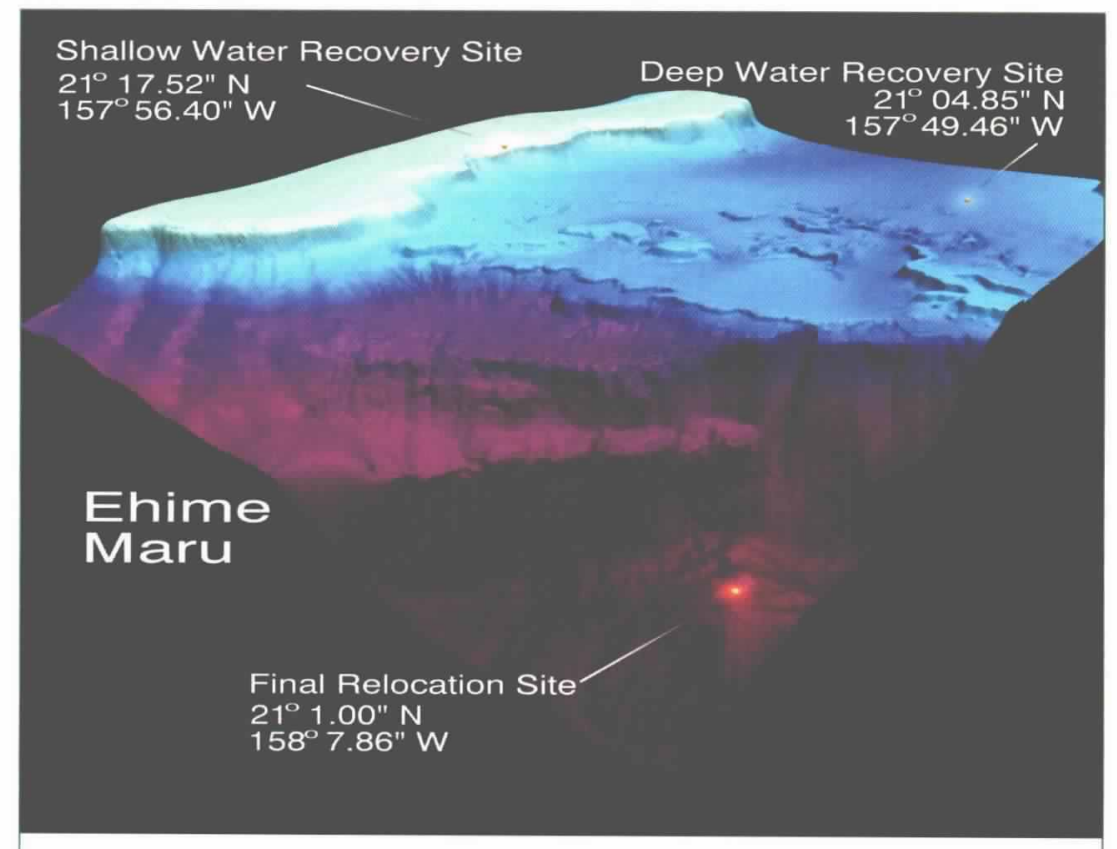

Figure 1. Bathymetric location of Deep Water Recovery Site (DWRS), Shallow Water Recovery Site (SWRS) and Final Relocation Site. on board, presenting a potential environmental hazard.

The sediments collected by the USNS Sumner core samples provided no surprises. The sediment did, however, offer difficulties at the DWRS. Under the original plan, two cables would be hydraulically bored under the Ehime Maru and these cables would be used to pull lifting plates under the hull. Repeated attempts at this technique failed as the engineers were unable to correctly steer the hydraulic jets. Finally, the engineers pulled a cable, which was looped around the stern, under the hull, lifted, and placed the stern lifting plate in position.

A similar attempt at the bow failed because it was buried more deeply in the sediment than the stern. A successful solution was found when it was determined that the Ehime Maru could be raised by placing lifting cables through the anchor hawse pipes on the bow. Throughout this entire rigging effort, conducted entirely by ROVs, disrupted sediment slowed the process. Whenever a vehicle or other equipment sits presented no surprises and no unexpected underwater peaks that would have required an indirect route from the DWRS to the SWRS.

The overall depth, however, presented a concern. Initially, the plan called for lifting the Ehime Maru up to within 30 meters of the lift ship, Rockwater II, on four strands of 11.5 centimeter-thick cable connected to a spreader assembly buoyantly suspended above the Ehime Maru. The ship was going to be raised by two 500 -ton capacity cranes lifting from the port and starboard sides of the Rockwater II. There were concerns that a lift cable on one side of the Rockwater II might break, causing the Rockwater II to rollover. As a result an incremental lift procedure was instituted. The lift and move would be conducted slowly by lifting the Ehime Maru 30 meters above the sea bottom and then by maintaining this 30 meter separation above the seafloor as the Rockwater II moved towards the SWRS. If any cables broke during this phase the resulting 30 meter drop of the Ehime Maru would not be far enough to pull the Rockwater II over. The lift of the final 500 meters would then occur in one powerful effort when Rockwater II was within two miles of the SWRS.

\section{Sedimentation Difficulties}

The Ehime Maru was found mostly intact and sitting upright on the ocean's floor. However, there was significant hull damage because of the impact of the USS Greeneville's rudder. Engineers were unsure whether the hull would hold together during the liftand-move phase of the planned operation. Also, an unknown amount of fuel and lubrication oil remained touched the bottom, visibility was reduced due to disturbed sediments. It generally took 30 to 45 minutes for the sediments to resettle and for adequate visibility to return.

\section{Surface Currents}

While bathymetry and bottom sediments remained important, the main oceanographic focus centered on understanding the movement of the surface waters of Mamala Bay. An understanding of this movement would allow the Navy to correctly position oil skimmers relative to the submerged ship and any oil leaks. An additional concern was to ensure all movements of the Ehime Maru were correctly timed to occur while westward surface currents moved away from Oahu, especially during the critical period when setting down the hull at the SWRS.

It was expected that the currents would be complex and difficult to forecast. The currents at the DWRS as measured by the USNS Sumner and her deployed ADCP revealed that the currents, both deep and shallow, were within the engineering capabilities of the designed lift techniques. However, as a precursor to understanding the critical surface currents at the SWRS and their impact on possible oil dispersion, preliminary assessment by the Naval Oceanographic Office stated,

"The mooring at the SWRS was placed at the edge of the shelf where water depth is about $42 \mathrm{~m}$. The mean residual flow was about 0.35 knots toward 260 degrees True (along-shore) at $4 \mathrm{~m}$ depth, toward the north at 0.002 knots at mid-depth, and 


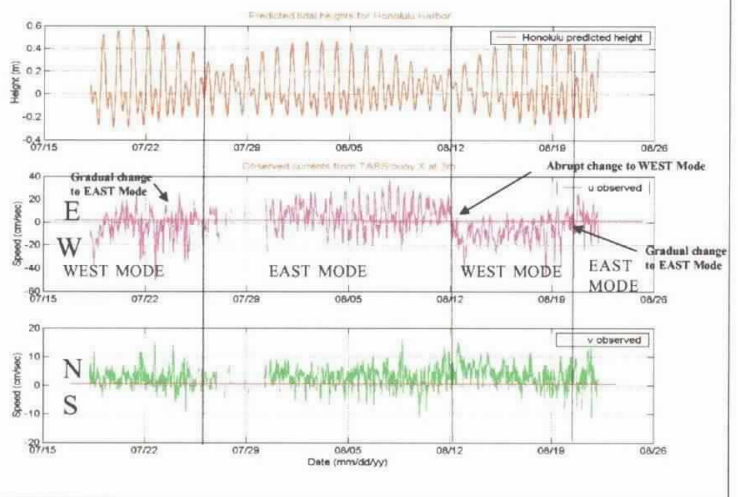

Figure 2. Tides and Currents near SWRS. (Top) Tide heights for Honolulu Harbor. (Middle) East/West current measurements showing dominant modes. (Bottom) Much smaller north/south current measurements.

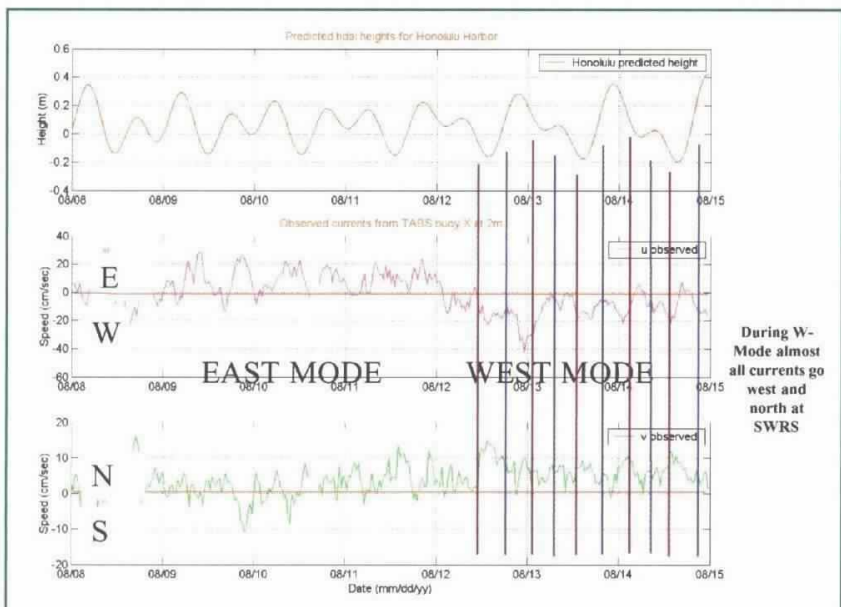

Figure 3. Annotation of both ebb (brown verticals) and flood (blue verticals) tide cycles during West Mode event show dominant westward surface motion.

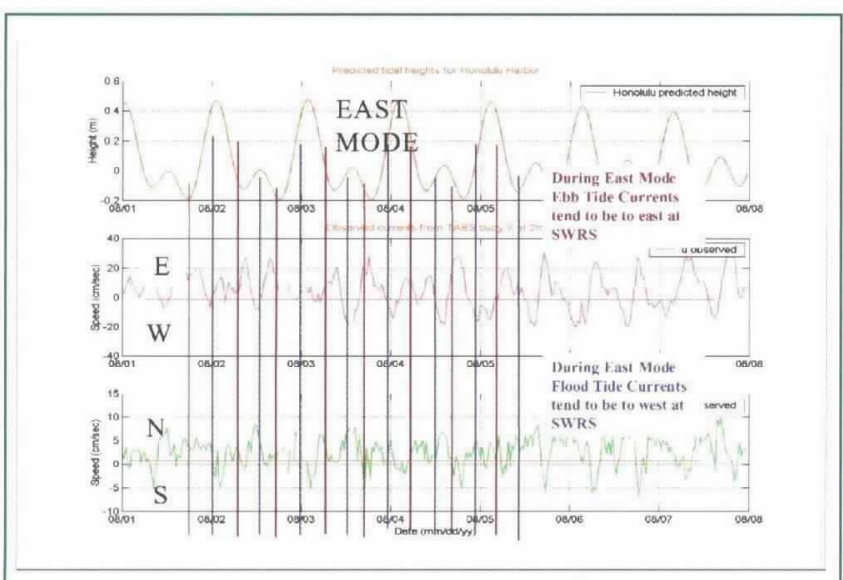

Figure 4. During East Mode ebb tides tend to drift east while during flood tides the motion reverses to the west. southward at 0.04 knots at the bottom. The mid-frequency currents were dominated by a 2.5 day period wave with a peak amplitude of 0.5 knots directed along-shore (about 80 degrees True). The origin or cause of this wave is presently unknown, and no attempt has been made to predict it as has been done for the tides in this region.

Maximum variability in the tidal currents occurred along-shore (80 degrees True) with maximum speeds of 0.5-0.7 knots. As with the deep recovery site, the tidal currents at the shallow recovery site were mixed, mainly semi-diurnal. The depthdependence of the tides indicated the presence of internal tides at the SWRS. Higher harmonics of the tides (amplitudes of 0.1 knots) were caused by shallow-water effects and increased the tidal prediction error. Prediction error of the tides at this mooring was $50 \%-60 \%$ in the east-west direction (approximately along-shore) and 65\%-85\% across-shore. The predictions appeared to perform well for the diurnal and semi-diurnal tides but were inadequate for shallow-water (higher harmonics) tides. The prediction often underestimated the peak velocities of the strongest tides by 30\%-50\%. Maximum velocities of the total measured surface currents were about 1 knot toward the west and 0.5-0.8 knots toward the east. At the bottom, maximum currents were approximately 0.6 knots (Carnes et al. 2001)."

Especially disturbing in this assessment was the difficulty in predicting the overall surface water motion. The surface currents that are observed at any given point on the sea are the combined result of wind forces, tides, the Earth's rotation and sea surface topography. These forces result in wind-driven currents, wind waves, tidal, inertial, and geostrophic currents. Geostrophic currents occur where there is a balance between the pressure gradient forces caused by the slope of the sea surface and the Coriolis force. The prediction of these resulting surface currents is complicated by the fact that the forces generating them are always changing (Lucas, 1978). Further, the underwater topography and internal waves contribute to the observed currents in complex and non-linear ways especially in shallow water (Hamilton et al., 1995).

Therefore, the best way to understand the surface currents for a particular shallow water site is to study the tide tables, observe the currents through instrumentation over many tidal cycles, and observe/record trends for the location of interest. This was accomplished at the critical SWRS. The USNS Sumner's installation of the TABS buoys was an essential element in this process.

\section{SWRS Observations and Measurements}

During mid-July to late August 2001, Michael Carron, Senior Oceanographer from the Naval Oceanographic Office, worked on monitoring the 
tides, analyzing the surface currents reported by the TABS buoys, and developing a trend analysis of the surface currents at the SWRS. Figures (2) through (4) detail that work.

Figure (2) shows three panels. The top panel is the predicted tidal heights for Honolulu Harbor, the middle panel is the measured east-west (u) currents at the TABS buoy located approximately one mile east of the SWRS, and the bottom panel is the measured north-south (v) currents from the same TABS buoy. In the middle panel the westerly mode can be seen at the beginning of the TABS series. It appears that the east mode is the normal mode (60 percent of time) and the west mode (40 percent) happens abruptly then relaxes to the east mode. Also note that the north/south component of the currents at the SWRS is slightly to the north, but only at about 0.1 knot. Note the scale change between middle and bottom panels.

Figures (3) and (4) shows the relationship between specific flood and ebb tides and the surface currents. The brown vertical lines note ebb tides while the blue vertical lines note the flood tides. During a west mode almost all currents go west and north at the SWRS. During an east mode ebb tide currents tend to be east at the SWRS, while during an east mode flood, the currents tend to be west at the SWRS.

This analysis led to the following conclusions:

- Primary surface drift is along isobaths in two distinct modes (East and West).

- There is a slight drift to the north during both modes.

- Transition from west to east mode usually starts less than a week after the onset of a west mode. Transition is gradual.

- Onset of west mode is unpredictable and possibly abrupt.

- Once a mode is established at the SWRS it can be expected to last approximately three days (Carron, 2001).

\section{Oil Dispersion Effects}

During the summer of 2001 while instrumentation was being assembled and readied for deployment in support of moving the Ehime Maru, the oceanographic team was joined by Glen Watabayashi, Oil Drift Modeler, Office of Release and Restoration, NOAA, in Seattle. His task was to determine how accidentally released oil would spread if released at the SWRS. During discussions on the data requirements for his oil dispersion models Watabayashi stated that oranges drift on the ocean surface and respond to the tides, winds and waves in a fashion very similar to oil.

Based on this, it was decided to conduct two experiments at the SWRS. A small craft was located and equipped with a case of 50 oranges and a global positioning system. During an ebb tide and a flood tide near the SWRS, 25 oranges each were dropped into the water and monitored as they moved, to learn more about surface water motion at the SWRS, especially any relationship between tides and trade winds. The drift data collected contributed to understanding the East and West Mode concept, verified the ebb and flood dynamics, and provided strong evidence that moderate to strong trade winds over the SWRS enhances westerly surface drift.

The effort, when combined with the data later measured by the TABS buoys enabled the development of Figure (5), Environmental risk factors timeline and decision matrix. This graphic provided the decision criteria in a Red-Yellow-Green, go, no-go format for the necessary winds, tides, daylight, Oil Dispersion Model Forecast and availability of oil skimming craft required 


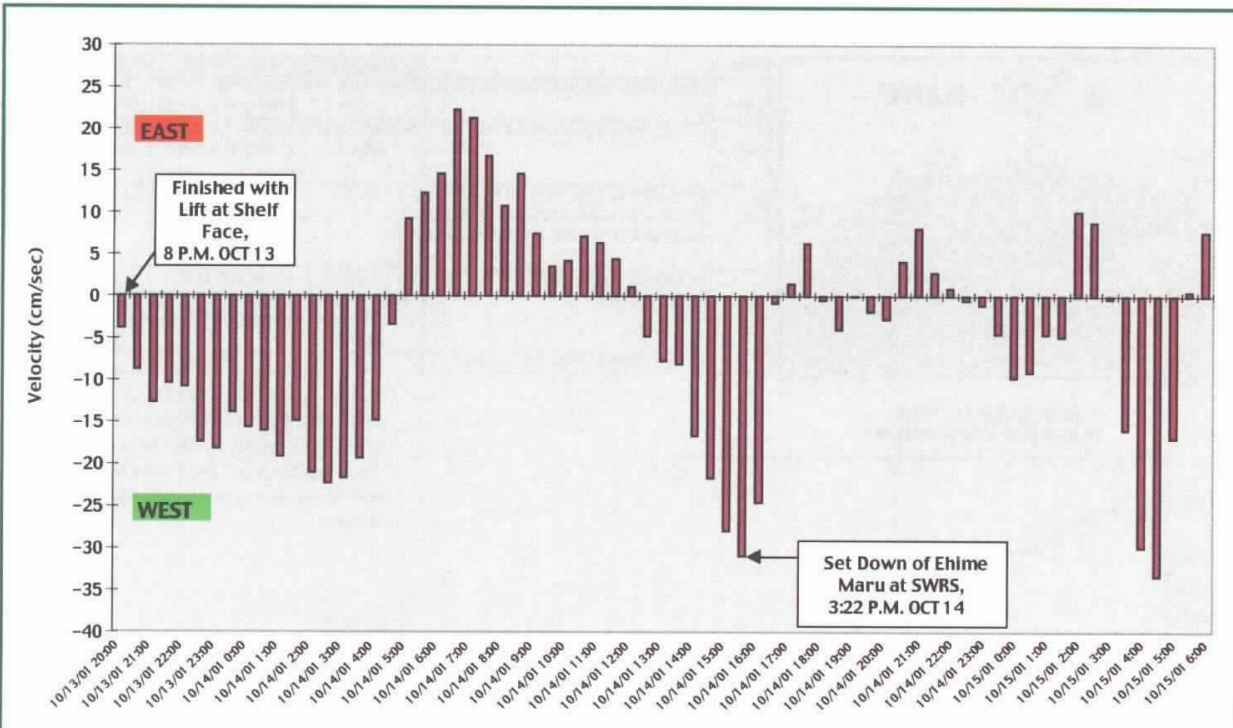

Figure 6. East-west ocean current components as measured near the SWRS during the relocation of the Ehime Maru.

transit. This decision was fortunate since during the night the Ehime Maru released diesel oil. Because the Ehime Maru was held in deeper, offshore water with strong trade winds, the oil did not reach any beaches (Moran, 2001).

Figure (6) shows the ocean currents during October 13-15. The surface currents during most of that period were in the West Mode and consequently, drifting west (Moran, 2001). The Ehime Maru was set down at the SWRS at 3:22 PM on October 14, 2001.

Because of Admiral Klemm's decision the Ehime Maru was set down in perfect environmental conditions. He attained his perfect "Green" decision matrix conditions with gusty northeast Trade Winds and almost perfect timing with the Mean Lower

to make a decision on the best time to set the Ehime Maru down at the SWRS. Green environmental conditions included northwest through east-northeast winds and tides that are to be at Mean Lower High Water plus one hour to Mean Lower Low Water. Unstated on the graphic but understood was that this specific tide condition should be selected to occur during a West Mode trend to best ensure any oil release during set down would drift west.

\section{The Lift and Transit to SWRS}

The Rockwater II lifted the Ehime Maru off the sea floor early on October 12, 2001, and slowly proceeded towards the SWRS accompanied by several other vessels. Leading the group was the USNS Sumner, which collected real-time current measurements, and on its flanks the Coast Guard cutters, Kiska and Washington, enforcing an off-limits zone. Nearby were several oil skimmers, followed by the USS Salvor with its ROV submerged and watching the Ehime Maru. The transit occurred without incident, and the Rockwater II and the convoy were able to transit further and lift faster then predicted. They arrived two miles from the SWRS on the evening of 13 October. Even though there were favorable winds and tides, the impending darkness made this a less then optimal time to proceed to the SWRS.

The oceanography support team, consisting of personnel from the Naval Oceanographic Office and the Naval Pacific Meteorology and Oceanography Center, Pearl Harbor, advised Admiral Klemm that conditions at their current location would carry any released oil away from the islands. They also stated that optimum conditions for set down at the SWRS would occur again in 16 hours. Admiral Klemm decided to halt the
High Water plus one hour at the SWRS. These were the best possible conditions for ensuring that no oil would reach any Hawaiian beach.

\section{Conclusion}

This mission came to a close at 3:48 PM on November 25, 2001, as the hull of the Ehime Maru was released into the depths southwest of Oahu. After almost 450 successful dives, eight of the bodies of the nine missing crewmen and many personal effects were recovered and returned to their families. No oil reached any Hawaiian beaches.

This operation, which successfully combined current state-of-the-art engineering skill with the best from the Navy Meteorology and Oceanography Community, completed a significant political, technical and oceanographic challenge for the Navy. [ed

\section{References}

Carnes, M.R., T. Best, K. Wood and O. Von Zweck, 2001: Physical Oceanography Basic Data Report Ehime Maru Recovery Support 17-28 June and 17-21 Jul 2002. NAVOCEANO Report.

Carron, M.J., 2001: Presentation to Ehime Maru Recovery Team, Pearl Harbor HI.

Hamilton, P., J. Singer and E. Waddell, 1995: Mamala Bay Study Ocean Current Measurements. SAIC Report.

Lucas, R.B., 1978: The Prediction of Oil Slick Trajectories at the Honolulu Harbor Channel Entrance. Hawaii Institute of Geophysics Publication.

Moran, J.R., 2001: After Action Report: Environmental Factors Risk Reduction during the Relocation of the Ehime Maru. Ehime Maru Recovery Team Report. 